\title{
Quantitative Trait Loci in Sweet Corn Associated with Partial Resistance to Stewart's Wilt, Northern Corn Leaf Blight, and Common Rust
}

\author{
A. F. Brown, J. A. Juvik, and J. K. Pataky
}

First and second authors: Department of Natural Resources and Environmental Sciences; and third author: Department of Crop Sciences, University of Illinois, Urbana 61801.

Accepted for publication 13 November 2000.

\begin{abstract}
Brown, A. F., Juvik, J. A., and Pataky, J. K. 2001. Quantitative trait loci in sweet corn associated with partial resistance to Stewart's wilt, northern corn leaf blight, and common rust. Phytopathology 91:293-300.

Partial resistance to Stewart's wilt (Erwina stewartii, syn. Pantoea stewartii), northern corn leaf blight (NCLB) (Exserohilum turcicum), and common rust (Puccinia sorghi) was observed in an $\mathrm{F}_{2: 3}$ population developed from a cross between the inbred sweet corn lines IL731a and W6786. The objective of this study was to identify quantitative trait loci (QTL) associated with partial resistance using restriction fragment length polymorphic markers. Phenotypic data were collected for 2 years for Stewart's wilt, NCLB, and common rust but, due to significant familyenvironment interaction, analysis was conducted individually on data

describing from 5.9 to $18 \%$ of the total phenotypic variability. Of six regions common in both years, three were associated with partial resistance to Stewart's wilt (chromosomes 4:07, 5:03, and 6:04), one was associated with NCLB (chromosome 9:05), and two were associated with common rust (chromosomes 2:04 and 3:04). The rust QTL on 3S mapped to within $20 \mathrm{cM}$ of the $r p 3$ locus and explained $17.7 \%$ of the phenotypic variability. Some of the QTL associated with partial resistance to the three diseases have been reported previously, and some are described here for the first time. Results suggest it may be possible to consolidate QTL from various elite backgrounds in a manner analogous to the pyramiding of major resistance genes. We also report here on two QTL associated with anthocyanin production on chromosomes 10:6 and 5:03 in the general location of the $a 2$ gene.
\end{abstract} from each year. In 2 years of evaluation for the three diseases, a total of 33 regions in the maize genome were associated with partial resistance
Additional keywords: genome mapping, Zea mays.
Stewart's bacterial wilt (Erwina stewartii (Smith) Dye, syn. Pantoea stewartii), northern corn leaf blight (NCLB) (Exserohilum turcicum), and common rust (Puccinia sorghi) are three of the most persistent diseases encountered by sweet corn producers in the Midwestern United States $(16,42)$. Epidemics of these diseases have increased in recent years due to favorable weather conditions, the susceptibility of some hybrids, and increased winter production of maize in the southern United States that leads to earlier arrival and higher levels of Puccinia sorghi in the Midwest (16,44).

The identification of disease-resistant germ plasm and incorporation of resistance in commercial hybrids can increase yields, lower production costs, and reduce use of pesticides. Racespecific or major gene resistance has been identified for Stewart's wilt, NCLB, and common rust $(14,17,21-26,38,48)$, but simply inherited resistance may result in selection for virulent races. For example, biotypes of Puccinia sorghi virulent on Rpl-D-resistant hybrids were recently identified in the Midwestern United States where the $\operatorname{Rpl-D}$ gene has been used successfully for the past 15 years to provide resistance in sweet corn to common rust (45).

Partial resistance to these diseases may be more durable than simply inherited resistance (55). Traditionally, partial resistance has been more difficult to transfer than simply inherited resistance due to its presumed multigenic nature. Backcrossing polygenic traits from unadapted lines with poor combining ability generally results in inferior inbreds. Molecular mapping techniques in combination with marker assisted selection, however, may enable breeders to identify and exploit these forms of resistance more effectively (57).

Corresponding author: J. A. Juvik; E-mail address: j-juvik@uiuc.edu

Publication no. P-2001-0102-01R

(C) 2001 The American Phytopathological Society
Partial resistance to Stewart's wilt is characterized by a restricted movement of the bacterium through the vascular system (3). Resistance to Stewart's wilt in a number of sweet corn inbreds related to IL677a, including IL731a, apparently is inherited simply (37). Ming et al. (38), using the Stewart's wilt-resistant maize inbred Ki14, identified a major quantitative trait loci (QTL) designated $s w 1$ on chromosome $1 \mathrm{~S}$ and a minor QTL on chromosome 9 that conferred partial resistance to Stewart's wilt.

Reactions to NCLB range from almost complete absence of the disease to complete susceptibility $(26,37)$. Partial resistance to NCLB is expressed as a reduction in lesion number and size and an increase in incubation period $(5,26)$. Jenkins $(28)$, using the resistant maize inbreds Mo21A and NC34 and chromosomal translocation stocks, identified QTL associated with partial resistance to NCLB on chromosomes $1 \mathrm{~S}, 3 \mathrm{~L}, 4 \mathrm{~S}, 4 \mathrm{~L}, 5 \mathrm{~L}$, and $7 \mathrm{~S}$. A similar approach was used by Brewster et al. (4) to identify regions on chromosomes $3,4 \mathrm{~S}$, and $6 \mathrm{~L}$ that were consistently associated with partial resistance in crosses of the resistant maize inbred Mo17 and susceptible translocation stocks. Freymark et al. $(12,13)$, also working with the inbred Mo17, used molecular markers to identify regions on chromosome $1 \mathrm{~S}, 3 \mathrm{~L}$, and $5 \mathrm{~S}$ that were associated with a reduction in lesion number and severity and to identify regions on $7 \mathrm{~L}$ and $8 \mathrm{~L}$ that were associated with a reduction in severity. Partial resistance to NCLB in Mo17 is primarily additive (5).

Partial resistance to common rust also has been noted and generally is expressed through components of the infection cycle, which result in fewer and smaller lesions or fewer uredinia (8, 29,41). Partial rust resistance also has resulted from longer latent periods (15). Lubberstedt et al. (35), using the European maize flint lines KW1265, D146, D145, and KW1292, identified 20 QTL conferring partial resistance to common rust distributed over all 10 chromosomes. Kerns et al. (30), working with a segregating population generated from a cross of FRMo17 $\times$ BS11(FR)c7, 
identified 32 molecular markers throughout the maize genome associated with partial rust resistance.

The inbred IL731a is closely related to IL677a, the source of the sugary enhancer ( $\mathrm{se}$ ) gene (11) that imparts improved eating quality characteristics. Lines derived from crosses with IL677a are widely used in commercial sweet corn hybrids. Some hybrids and inbreds derived and related to IL677a have moderate to high levels of partial resistance to Stewart's wilt, NCLB, and common rust $(31,37,41,43)$. These lines also have a noticeably higher purple pigmentation associated with the amount of anthocyanins than most other sweet corn lines. The objectives of this study was to map QTL associated with partial resistance to Stewart's wilt, $\mathrm{NCLB}$, and common rust in an $\mathrm{F}_{2: 3}$ population from a cross between the inbreds IL731a and W6786 and to map QTL associated with anthocyanin pigmentation.

\section{MATERIALS AND METHODS}

Plant materials. Three inbreds (IL731a, IL677a, and W6786) and a minimum of $157 \mathrm{~F}_{2: 3}$ families per experiment from the cross of IL731a and W6786 were planted at the University of Illinois South Farm on 17 May 1994, 20 May 1995, and 22 May 1996. The resistant inbred IL731a was originally derived from a cross between the inbred IL677a and the hybrid 'Golden Sensation' (47). Standard sweet corn production practices were followed. Each disease was a separate experiment. The experimental design was a randomized complete block with two replicates. Each experimental unit was a single row of approximately 15 plants. Stewart's wilt was evaluated in 1994 and 1995. NCLB and common rust were evaluated in 1994 and 1996. Plants were inoculated in all experiments.

Stewart's wilt. Plants at the two- to five-leaf stage were inoculated with Erwina stewartii on 7 and 21 June 1994 and 20 and

TABLE 1. Analysis of variance for Stewart's wilt, northern corn leaf blight (NCLB), and common rust ratings of the families in the $\mathrm{F}_{2: 3}$ population from the cross of IL731a $\times$ W6786

\begin{tabular}{|c|c|c|c|c|c|c|}
\hline \multirow[b]{2}{*}{ Source $^{\mathrm{a}}$} & \multicolumn{2}{|c|}{ Stewart's wilt ${ }^{\mathrm{b}}$} & \multicolumn{2}{|c|}{ NCLB } & \multicolumn{2}{|c|}{ Common rust } \\
\hline & df & MS & $\mathrm{df}$ & MS & df & MS \\
\hline Block (year) & 2 & 0.41 & 2 & $87.24 * *$ & 2 & $3.40 * *$ \\
\hline Year & 1 & 3.41 & 1 & $6,254.13 * *$ & 1 & 0.04 \\
\hline Families & 189 & $2.80 * *$ & 209 & $78.04 * *$ & 209 & $2.32 * *$ \\
\hline Families $\times$ year & 167 & $1.16^{*}$ & 146 & $36.80 * *$ & 145 & $0.73^{* *}$ \\
\hline Error & 326 & 0.90 & 332 & 16.25 & 345 & 0.29 \\
\hline$R^{2}$ & $\ldots$ & 0.72 & $\ldots$ & 0.85 & $\ldots$ & 0.86 \\
\hline $\mathrm{CV}$ & $\ldots$ & 23.9 & $\ldots$ & 19.7 & $\ldots$ & 20.2 \\
\hline
\end{tabular}

${ }^{a} R^{2}=$ fraction of phenotypic variation explained by model; and $\mathrm{CV}=$ coefficient of variation.

${ }^{\mathrm{b}} \mathrm{df}=$ degrees of freedom; MS $=$ mean square error; $*=$ significant at $P \leq$ $0.05 ; * *=$ significant at $P \leq 0.01$.
26 June 1995 using the pinprick method (2,6). Inoculum was prepared as described previously (51). Plants were rated for Stewart's wilt symptoms on 14 July 1994 and 8 August 1995 using a 1 to 9 scale described previously (51). Each row was assigned two ratings which reflected the predominate reaction and variation in that row.

NCLB. Spore suspensions of Exserohilum turcicum races 0 and 1 in an approximately 1:1 ratio at a concentration of approximately $10^{3}$ conidia per $\mathrm{ml}$ were sprayed into whorls at the threeto five-leaf stages on 13, 23, and 28 June 1994 and 19 and 27 June 1996. Exserohilum turcicum was originally isolated from corn grown in central Illinois and cultured as previously described (37). Severity of NCLB was assessed on a row basis on 4 August 1994 and 22 August 1996, based on the percentage of the total leaf area affected using a slightly modified version of the standard diagram of Elliot and Jenkins (10).

Common rust. Uredinospores of Puccinia sorghi, collected the previous summer in Champaign, IL were suspended in water with a drop of Tween 80 (Sigma-Aldrich, St. Louis) and were sprayed into plant whorls at the three- to six-leaf stage on 15, 23, and 28 June 1994 and 18, 20, and 24 June 1996. Severity of rust was rated on a row basis on 4 August 1994 and 22 August 1996 using a modified Peterson scale (46) to measure relative percentage of total leaf area infected.

Anthocyanin. Plants at the fresh market harvest stage were scored for anthocyanin concentration based on visual assessments of purple pigmentation of leaves, husks, stalks, and tassels. Plants were scored 0 (little or no purple pigmentation), 1 (moderate purple pigmentation), or 2 (abundant and strong purple pigmentation).

QTL markers and data analysis. DNA isolation, restriction, Southern blotting, and linkage map construction have been described previously (52). Briefly, 88 restriction fragment length polymorphic (RFLP) probes, provided by the Brookhaven National Laboratory (bnl), Pioneer Hi-Bred International (phb and npi), and the University of Missouri-Columbia (umc), three cDNA probes ( $s h 1, s h 2$, and $d h n 1)$, and two mutant phenotypic markers (a2 and sel) were used to construct a linkage map spanning all 10 chromosomes with an average interval distance of $18.8 \mathrm{cM}$ (52). Linkage maps were constructed using the kosambi mapping function of the MAPMAKER program (33). Equal amounts of leaf tissue were harvested for DNA extraction from $25 \mathrm{~F}_{2: 3}$ plants. Phenotypic data from each experiment was analyzed for genotypic effects and genotype-environment interactions using the PROC GLM procedure of SAS (SAS Institute, Cary, NC). Broad-based heritability, $\delta_{\mathrm{g}}^{2} /\left(\delta^{2} / \mathrm{re}+\delta^{2}{ }_{\mathrm{ge}} / \mathrm{e}+\delta_{\mathrm{g}}^{2}\right)$, was estimated for the three diseases on a family mean basis (19) and $90 \%$ confidence intervals were calculated (32). Composite interval analysis (18), which uses multiple regression with selected markers as cofactors, was performed with Plabqtl version 1.1 (53). Cofactors were selected for each trait by stepwise regression with the final model that

TABLE 2. Means, standard deviations (SD), and ranges of Stewart's wilt, northern corn leaf blight (NCLB), and common rust ratings for parental lines and derived sweet corn $\mathrm{F}_{2: 3}$ families from the cross of IL731a $\times$ W6786

\begin{tabular}{|c|c|c|c|c|c|c|c|}
\hline \multirow[b]{2}{*}{ Disease and year ${ }^{\mathrm{a}}$} & \multicolumn{2}{|c|}{ Parental lines } & \multicolumn{3}{|c|}{$\mathrm{F}_{2: 3}$ families } & \multirow[b]{2}{*}{$H^{2 \mathrm{~b}}$} & \multirow[b]{2}{*}{$\mathrm{CI}^{\mathrm{c}}$} \\
\hline & IL731a & W6786 & Mean & SD & Range & & \\
\hline \multicolumn{8}{|l|}{ Stewart's wilt } \\
\hline 1994 & 2.2 & 6.7 & 3.9 & 1.5 & $1.7-7.2$ & $\ldots$ & \\
\hline \multicolumn{8}{|l|}{ NCLB } \\
\hline 1994 & 15.0 & 25.0 & 24.0 & 5.9 & $10.0-40.0$ & & \\
\hline 1996 & 8.5 & 28.5 & 16.9 & 6.4 & $5.5-35.0$ & 0.54 & $0.38-0.64$ \\
\hline
\end{tabular}

${ }^{a}$ Stewart's wilt rated from 1 to 9, NCLB rated from 0 to 100\% leaf area infected, and rust rated 0 to 100\% leaf area infected in 1994 and 1 to 9 in 1996.

${ }^{\mathrm{b}} H^{2}$ estimates based on $\delta_{\mathrm{g}}^{2} /\left(\delta^{2} / \mathrm{re}+\delta^{2} \mathrm{ge} / \mathrm{e}+\delta^{2}\right)$, data averaged over 2 years.

${ }^{\mathrm{c}}$ Confidence intervals on $H^{2}$ estimates (31). 
minimized Akaike's information criterion with penalty 3.0 (27). A $\log$ of the likelihood ratio (LOD) score of 2.0 was used to declare a putative QTL. This level was chosen to minimize type II errors and because we were principally interested in those QTL that were detected in both years because they are likely to be the most stable. As is the common practice, estimates of QTL location were obtained where the LOD score assumes its maximum value in the region. Support intervals represent a LOD score drop off of 1.0 on either side of the maximum LOD score value. The "cross" command of Plabqtl was used to generate 100 partial data sets containing four-fifths of the original data set (53). Composite interval analysis was conducted on these partial data sets to provide a validation of QTL presence and position (54). A frequency distribution of significant QTL position (based on maximum likelihood scores) was generated from these partial data sets and compared with those chromosomal positions where significant QTL were detected in both years using the complete data sets. The ratio d/a was used to determine the type of gene action. Gene action is described as additive if $\mathrm{d} / \mathrm{a}$ is 0 to 0.2 , partially dominant if $\mathrm{d} / \mathrm{a}$ is from 0.21 to 0.80 , dominant if $\mathrm{d} / \mathrm{a}$ is from 0.81 to 1.20 , and overdominant if $\mathrm{d} / \mathrm{a}$ is $>1.20$ (50). QTL were declared to be common between the years if their confidence intervals overlapped, the resistance allele was contributed by the same parent in both years, and the QTL mapped to within $20 \mathrm{cM}$ of each other.

\section{RESULTS}

Disease reactions. Analysis of variance for each disease detected significant differences among families and family-year interactions (Table 1). Block effects were significant for NCLB and for common rust. When data from both years were combined, the heritability of disease ratings for Stewart's wilt, NCLB, and common rust was $0.58,0.54$, and 0.71 , respectively (Table 2 ). The distribution of disease ratings was approximately normal for all diseases in each year (Figs. 1 to 3). IL731a was rated among the most resistant lines for each disease, as was IL677, which was included as a resistant check in all experiments. The reaction of W6786 was among the most susceptible families for Stewart's wilt and NCLB (Figs. 1 and 2) but was intermediate in reaction to common rust (Fig. 3). The means and the range of the Stewart's wilt disease and common rust ratings were comparable in the two years of testing (Figs. 1 and 3 and Table 2). NCLB was more severe in 1994 than in 1996 (Fig. 2 and Table 2). The year effect was significant for NCLB in the analysis of variance (Table 1).

QTL analysis of Stewart's wilt. A total of 11 regions on seven chromosomes were associated with Stewart's wilt ratings in at least 1 year of analysis, of which 3 were detected in both years (Table 3). Ten QTL accounted for $40.3 \pm 5.6 \%$ of the phenotypic variability in Stewart's wilt ratings in 1994, and five QTL accounted for $33.3 \pm 6.0 \%$ in 1996 (Table 3). Gene action of these QTL were predominately additive. The three QTL associated with disease severity in both years were in bins 4:07, 5:03, and 6:04 (Fig. 4). Based on data from both years, the QTL with the largest effect was in bin 6:04 and accounted for $19.8 \%$ of the phenotypic variability. The QTL alleles in bins 5:03 and 6:04 were partially dominant. The QTL allele on chromosome 4 was contributed from the susceptible parent W6786, while those on chromosomes 5 and 6 were from the resistant parent IL731a.

QTL analysis of NCLB. Thirteen regions distributed over eight chromosomes were significantly associated with NCLB severity in at least 1 year of analysis, of which one was detected in both years (Table 4). Seven QTL accounted for $30.1 \pm 5.6 \%$ of the phenotypic variability in NCLB disease ratings in 1994, whereas seven QTL accounted for $46.0 \pm 5.8 \%$ in 1996 . Gene action of these QTL alleles were additive to overdominant. Individual QTL explained between 5.2 and $19.5 \%$ of the phenotypic variability. A single QTL located in bin 9:05 was detected in both years (Table 4; Fig. 4) and was dominant in 1994 and 1996. The resistant allele at this QTL originated from IL731a.

QTL analysis of common rust. Nine regions on six chromosomes were significantly associated with rust severity in at least 1 year of analysis, of which two were associated in both years (Fig. 4). Seven QTL accounted for $41.4 \pm 5.5 \%$ of the phenotypic variability in rust ratings in 1994 and four QTL accounted for $23.8 \pm 5.9 \%$ in 1996 (Table 5). Gene action for these QTL was primarily partial to complete dominance. A QTL in bin 3:04 accounted for $17.7 \%$ of the phenotypic variability in 1994 and $7.3 \%$ in 1996. A second linked QTL accounted for an additional $7.4 \%$ of phenotypic variability in 1996. When data from both years were combined, a single QTL in bin 3:04 described 20\% of phenotypic variability. In both years, the analysis positioned the common QTL at $14 \mathrm{cM}$ distal to marker umc50. A QTL was de-
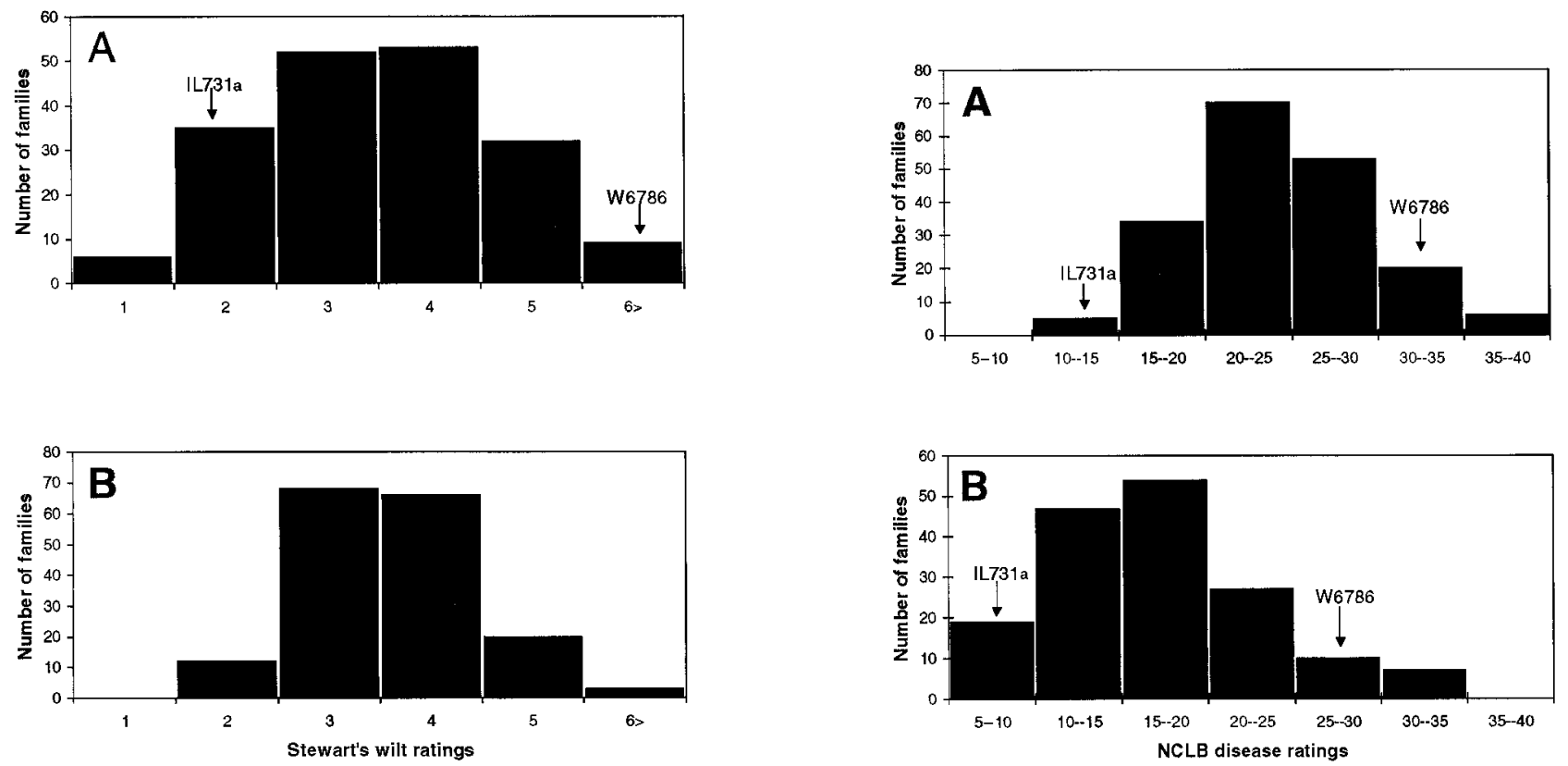

Fig. 1. Distribution of Stewart's wilt ratings in A, 1994 and B, 1995 in $F_{2: 3}$ families from the cross of IL731a $\times$ W6786. Stewart's wilt ratings were based on a 1 to 9 scale, in which $1=$ limited symptoms and $9=$ dead plants.

Fig. 2. Northern corn leaf blight (NCLB) disease severity in A, 1994 and B, 1996 in $\mathrm{F}_{2: 3}$ families from a population generated from the cross IL731a $\times$ W6876. NCLB severity is based on a percentage of infected leaf area. 
tected in both years in bin 2:04 and explained 7.1 and $8.6 \%$ of the phenotypic variability in 1994 and 1996, respectively. The QTL allele in 3:04 was contributed by the resistant parent IL731a, whereas the QTL on 2:04 came from the susceptible parent W6786. The QTL allele in 3:04 was dominant in 1994 and partially dominant in 1996. The QTL allele in 2:04 was partially dominant in 1994 and additive in 1996.

QTL analysis of anthocyanin. Two regions on chromosomes 5:03 and 10:06 were identified in 1996 that accounted for 18.8 and $7.1 \%$ of the phenotypic variability, respectively (Table 6; Fig. 4). The QTL on 5:03 was contributed by IL731a, whereas the QTL on 10:06 came from W6786. Both QTL alleles associated with enhanced pigmentation acted in a partially dominant manner.

Validation of QTL position. For those QTL that were observed in both years, the analysis of the 100 partial data sets identified significant QTL within the original confidence intervals in 16 to $97 \%$ of the simulations (Table 7). The peak of the frequency distribution generated from these sets positioned the QTL within $4 \mathrm{cM}$ of the location generated by the original data set.
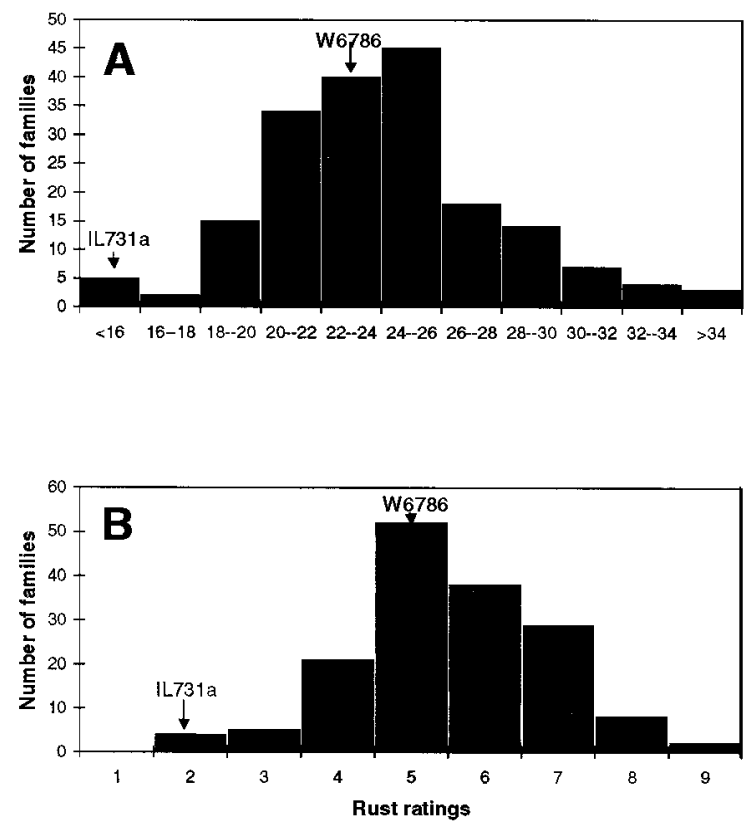

Fig. 3. Common rust ratings of $F_{2: 3}$ families from a cross of IL731a $\times$ W6786. Rust ratings were based on $\mathbf{A}$, a 1 to 9 scale in 1994 and $\mathbf{B}$, percentage of leaf infected in 1996.

\section{DISCUSSION}

Some of the QTL identified in this article have mapped to regions previously described to be associated with disease resistance. Freymark $(12,13)$ suggested that linkage group 7L (bins 7:03-7:04) was important in reducing both NCLB severity and size of lesions. Although this region was significant in both years of our study and contributed approximately $8.0 \%$ to the phenotypic variability, the QTL mapped to adjacent intervals in the 2 years. This likely represents the action of a single QTL whose position has been influenced by a linked QTL on the same linkage group. Markers common to both studies suggest that this QTL from our study maps within $20 \mathrm{cM}$ of the previous investigation. The same author identified QTL in bins 1:01 and 3:08 that mapped to similar locations as year-specific QTL in our study. Ming et al. (38) recently identified a major QTL ( $s w 1)$ that provided resistance to Stewart's wilt in bin 1:05. In our study, this arm was significant in both years but QTL mapped to different locations. Lubberstedt et al. (35) identified QTL conferring partial resistance to common rust in maize inbreds in bins 1:03, 2:10, and 4:03. These bins correspond to locations identified in at least 1 year of our study.

A major QTL associated with partial resistance to common rust is described here in bin 3:04. Based on markers found in our study and published in maize genetic maps (7), this QTL can be placed within $10 \mathrm{cM}$ of the Rp3 locus (49). Breeders and pathologists have debated whether the nature and genetic regulation of partial (general or horizontal) resistance is similar to that of major gene or vertical resistance $(40,55)$. Theories have been proposed that partial resistance is a residual function of defeated major genes (39). In other experiments, QTL have been described in locations that correspond to major resistance genes $(9,34,56)$. Resistance genes in maize, frequently, are found in clusters (36), and the statistical power of current mapping techniques does not allow for the resolution of whether these genes are contiguous or allelic to known genes. The development of near-isogenic lines (58) and use of fine mapping techniques using probes associated with the Rp3 locus (49) may be required to determine if the QTL conferring partial resistance to common rust in this study is linked or allelic to $R p 3$.

The identification of a major QTL that confers partial resistance to common rust in bin 3:04 contrasts with the results of Kim and Brewbaker (31), who reported that resistance to common rust in IL677a was conditioned by a gene closely linked to $R p 1$ locus on chromosome 10. This discrepancy may be due to different reactions to populations of Puccinia sorghi with different virulence or populations from crosses with IL677a that are not segregating for

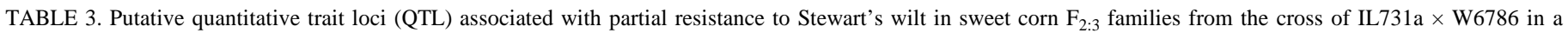
single environment over 2 years

\begin{tabular}{|c|c|c|c|c|c|c|c|c|c|c|c|c|c|c|c|c|c|c|c|c|c|c|c|}
\hline \multirow[b]{2}{*}{$\operatorname{Bin}^{a}$} & \multicolumn{8}{|c|}{$1994^{\mathrm{b}}$} & \multicolumn{8}{|c|}{1996} & \multicolumn{7}{|c|}{ Combined } \\
\hline & Pos & Mark & SI & $R^{2}$ & LOD & Add & Dom & PS & Pos & Mark & SI & $R^{2}$ & LOD & Add & Dom & PS & Pos & SI & $R^{2}$ & LOD & Add & Dom & $\operatorname{Ref}^{\mathrm{c}}$ \\
\hline 1:01 & $\ldots$ & $\ldots$ & $\ldots$ & $\ldots$ & $\ldots$ & $\ldots$ & $\ldots$ & $\ldots$ & 0 & b10.38 & $0-13$ & 6.5 & 2.39 & -0.23 & -0.06 & W & 0 & $0-18$ & 6.0 & 2.4 & -0.27 & 0.06 & 37 \\
\hline 1:04 & 114 & n447 & 95-134 & 9.0 & 3.73 & 0.43 & 0.81 & I & $\ldots$ & $\ldots$ & $\ldots$ & $\ldots$ & $\ldots$ & $\ldots$ & $\ldots$ & $\ldots$ & $\ldots$ & $\ldots$ & $\ldots$ & $\ldots$ & $\ldots$ & $\ldots$ & 37 \\
\hline $1: 10$ & 143 & u128 & $135-160$ & 7.9 & 3.29 & -0.90 & -0.49 & W & 192 & $u 42 b$ & $189-200$ & 8.1 & 3.01 & -0.26 & 0.11 & $\mathrm{~W}$ & 185 & $167-198$ & 5.4 & 2.18 & -0.26 & 0.05 & $\ldots$ \\
\hline 2:04 & 56 & u134 & 47-64 & 15.5 & 6.58 & 0.63 & 0.09 & I & $\ldots$ & $\ldots$ & $\ldots$ & $\ldots$ & $\ldots$ & $\ldots$ & $\ldots$ & $\ldots$ & 52 & $35-71$ & 5.2 & 2.11 & 0.25 & 0.12 & $\ldots$ \\
\hline 4:01 & 0 & u123 & $0-9$ & 7.7 & 6.58 & 0.62 & 0.09 & I & $\ldots$ & $\ldots$ & $\ldots$ & $\ldots$ & $\ldots$ & $\ldots$ & $\ldots$ & $\ldots$ & 0 & $0-12$ & 6.8 & 2.35 & 0.10 & 0.33 & $\ldots$ \\
\hline 4:07 & 216 & n593 & $196-224$ & 6.1 & 2.49 & -0.38 & 0.12 & W & 183 & $\mathrm{n} 410$ & $165-192$ & 6.4 & 2.37 & -0.26 & 0.08 & W & 172 & $163-192$ & 7.6 & 3.14 & -0.31 & -0.11 & $\ldots$ \\
\hline 5:03 & 86 & $a 2$ & $75-87$ & 7.5 & 3.11 & 0.49 & 0.19 & I & 93 & $a 2$ & 85-101 & 14.9 & 5.81 & 0.37 & 0.02 & I & 123 & $110-129$ & 10.2 & 4.26 & 0.31 & 0.09 & $\ldots$ \\
\hline 6:04 & 90 & n560 & 80-101 & 17.7 & 7.73 & 0.80 & -0.39 & I & 86 & n560 & 50-107 & 6.7 & 2.50 & 0.21 & -0.40 & I & 85 & 75-94 & 19.8 & 8.75 & 0.62 & -0.29 & $\ldots$ \\
\hline $6: 05$ & 153 & dhn 1 & $128-171$ & 5.8 & 2.30 & -0.39 & -0.27 & W & $\ldots$ & $\ldots$ & $\ldots$ & $\ldots$ & $\ldots$ & $\ldots$ & $\ldots$ & $\ldots$ & $\ldots$ & $\ldots$ & $\ldots$ & $\ldots$ & $\ldots$ & $\ldots$ & $\ldots$ \\
\hline 7:03 & 44 & u110 & 28-71 & 5.8 & 2.38 & 0.46 & -0.10 & I & $\ldots$ & $\ldots$ & $\ldots$ & $\ldots$ & $\ldots$ & $\ldots$ & $\ldots$ & $\ldots$ & $\ldots$ & $\ldots$ & $\ldots$ & $\ldots$ & $\ldots$ & $\ldots$ & $\ldots$ \\
\hline 10:01 & 13 & b10.17 & $0-23$ & 8.3 & 3.37 & 0.44 & -0.16 & I & $\ldots$ & $\ldots$ & $\ldots$ & $\ldots$ & $\ldots$ & $\ldots$ & $\ldots$ & $\ldots$ & 12 & $0-34$ & 2.22 & 5.5 & 0.28 & 0.12 & $\ldots$ \\
\hline
\end{tabular}

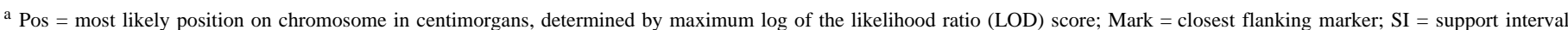
indicates a 1 LOD score drop off from maximum score; $R^{2}=$ percent phenotypic variance explained by QTL; LOD = maximum LOD score; Add = additivity, $1 / 2(\mathrm{QQ}-\mathrm{qq})$; Dom = dominance gene action, 1/2 [(2Qq) - QQ - qq]; and PS = parental source of allele (I = IL731a; W = W6786).

b Chromosomal locations dissected into bins by marker location according to Maize Genetics Newsletter.

${ }^{c}$ Relevant citations of previously identified QTL in same bin. 
the same alleles. IL677a, and sister lines such as IL731 may have a broader based resistance to common rust than previously reported.

A number of QTL are reported here for the first time. None of the QTL that were consistent between the years in the present study for partial resistance to Stewart's wilt have been previously reported. Similarly, QTL in bins 9:04 and 2:04 that confer partial resistant to NCLB and common rust, respectively, have not previously been associated with these regions of the maize genome.

The cross command of Plabqtl was used to generate a set of partial data sets to provide a validation of QTL presence and position that is independent of potential genotypic sampling effects. As might be expected, the percentage of these partial data sets which correctly identified a significant QTL within the original data sets' confidence interval was proportional to the effect of the individual QTL and its associated LOD score. The putative QTL on chromosome 4 associated with partial resistance to Stewart's wilt had marginal LOD scores in both years (2.49 and 2.37) and was identified only $16 \%$ of the time in the partial data sets from 1994. Taken together, this would suggest that the QTL in question is relatively minor, at best. Conversely, the best results occurred with the common rust data where a QTL on chromosome 3 was identified as being responsible for $20 \%$ of the phenotypic variability and was also identified by 96 and $97 \%$ of the partial data sets in 1994 and 1996, respectively. In more than 90\% of the data

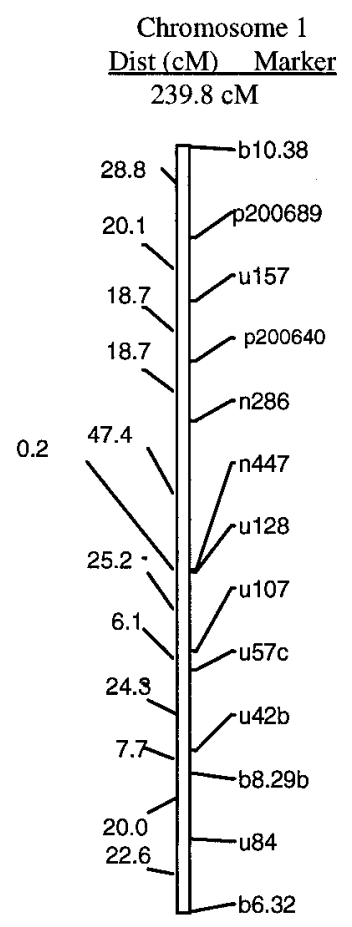

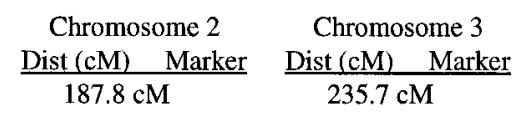
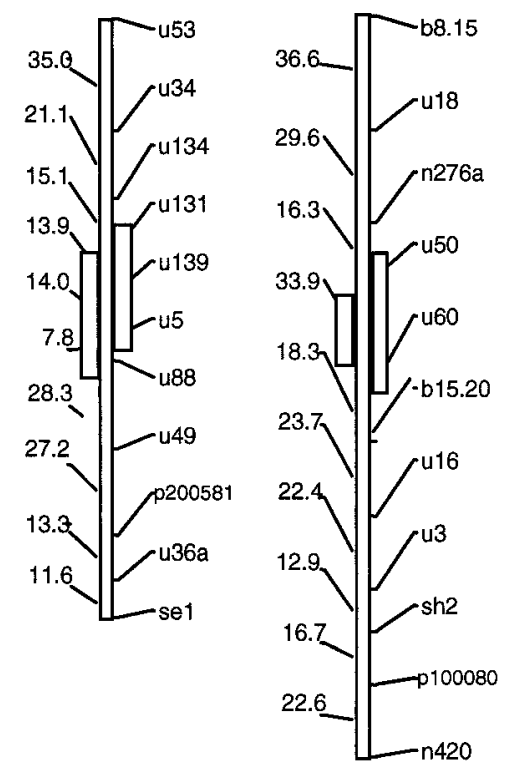
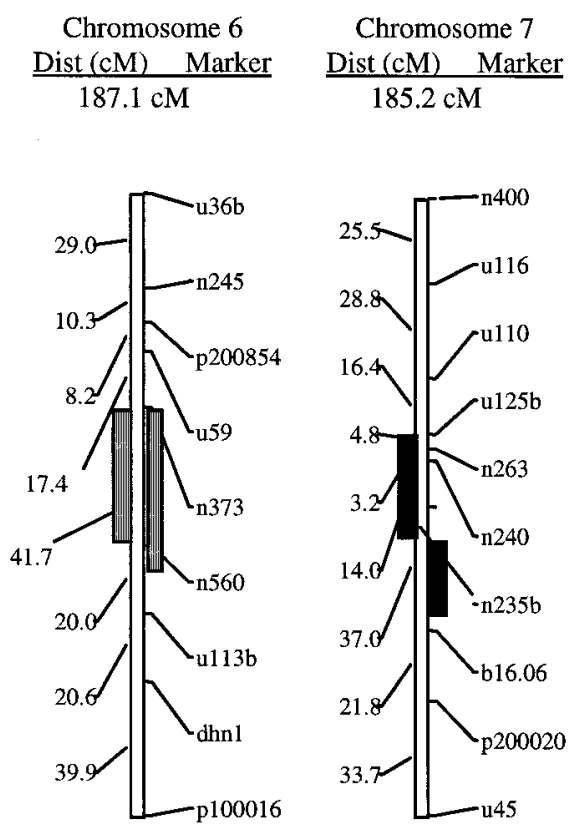

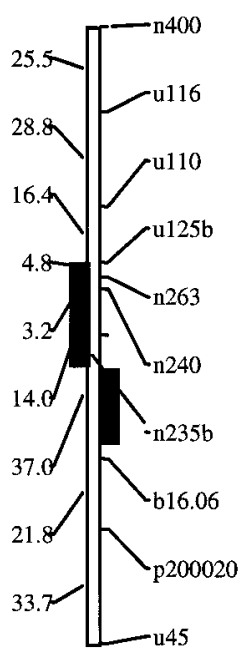

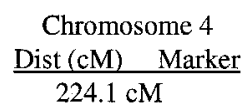

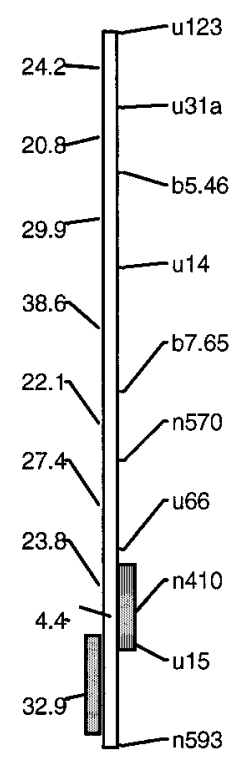

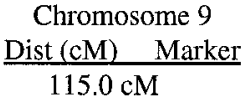

Chromosome 10 Dist (cM) Marker $104.2 \mathrm{cM}$

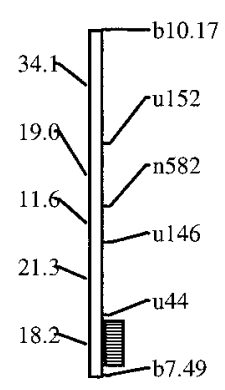

Chromosome 5
Dist (cM) Marker
$198.4 \mathrm{cM}$

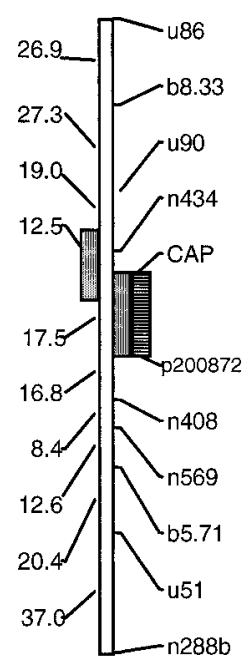

\section{Chromosome 8
Dist (cM) Marker $105.0 \mathrm{cM}$}

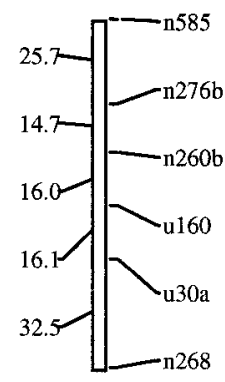

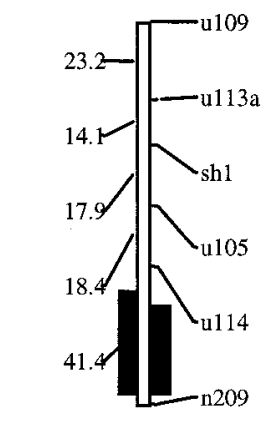

Common Rust
Stewart's wilt

$\mathrm{NCLB}$

Fig. 4. Genetic linkage map of sweet corn cross IL731a $\times$ W6876 obtained with $F_{2: 3}$ families and restriction fragment length polymorphism markers. Shaded intervals to the left of the chromosome indicate quantitative trait loci (QTL) confidence intervals from 1994. Shaded areas to the right of the chromosome indicate QTL confidence intervals from second year of analysis (1995 for Stewart's wilt, 1996 for Northern corn leaf blight [NCLB] and common rust). Anthocyanin QTL from 1996 are placed on right side of chromosome. 


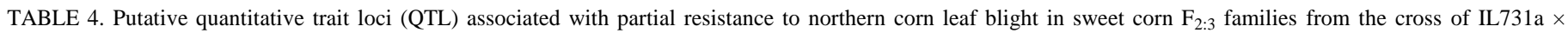
W6786 in a single environment over 2 years

\begin{tabular}{|c|c|c|c|c|c|c|c|c|c|c|c|c|c|c|c|c|c|c|c|c|c|c|c|}
\hline \multirow[b]{2}{*}{$\operatorname{Bin}^{a}$} & \multicolumn{8}{|c|}{$1994^{\mathrm{b}}$} & \multicolumn{8}{|c|}{1996} & \multicolumn{7}{|c|}{ Combined } \\
\hline & Pos & Mark & SI & $R^{2}$ & LOD & Add & Dom & PS & Pos & Mark & SI & $R^{2}$ & LOD & Add & Dom & PS & Pos & SI & $R^{2}$ & LOD & Add & Dom & $\operatorname{Ref}^{c}$ \\
\hline 1:01 & 28 & b10.38 & $17-39$ & 5.5 & 2.24 & -1.41 & 0.81 & W & $\ldots$ & $\ldots$ & $\ldots$ & $\ldots$ & $\ldots$ & $\ldots$ & $\ldots$ & $\ldots$ & $\ldots$ & $\ldots$ & $\ldots$ & $\ldots$ & $\ldots$ & $\ldots$ & 11 \\
\hline 1:03 & $\ldots$ & $\ldots$ & $\ldots$ & $\ldots$ & $\ldots$ & $\ldots$ & $\ldots$ & $\ldots$ & 87 & n286 & $85-108$ & 6.0 & 2.19 & 2.56 & -0.72 & I & $\ldots$ & $\ldots$ & $\ldots$ & $\ldots$ & $\ldots$ & $\ldots$ & $\ldots$ \\
\hline 1:07 & 133 & n447 & $114-134$ & 9.9 & 4.33 & 2.83 & 0.31 & I & $\ldots$ & $\ldots$ & $\ldots$ & $\ldots$ & $\ldots$ & $\ldots$ & $\ldots$ & $\ldots$ & 113 & $93-134$ & 6.8 & 3.14 & 2.60 & 0.19 & $\ldots$ \\
\hline 1:09 & 144 & u107 & $136-165$ & 8.0 & 3.34 & -5.07 & 0.90 & $\mathrm{~W}$ & $\ldots$ & $\ldots$ & $\ldots$ & $\ldots$ & $\ldots$ & $\ldots$ & $\ldots$ & $\ldots$ & $\ldots$ & $\ldots$ & $\ldots$ & $\ldots$ & $\ldots$ & $\ldots$ & $\ldots$ \\
\hline $1: 11$ & $\ldots$ & $\ldots$ & $\ldots$ & $\ldots$ & $\ldots$ & $\ldots$ & $\ldots$ & $\ldots$ & 239 & u84 & $224-239$ & 8.5 & 2.27 & -2.21 & 0.21 & W & $\ldots$ & $\ldots$ & $\ldots$ & $\ldots$ & $\ldots$ & $\ldots$ & $\ldots$ \\
\hline 2:05 & $\ldots$ & $\ldots$ & $\ldots$ & $\ldots$ & $\ldots$ & $\ldots$ & $\ldots$ & $\ldots$ & $\ldots$ & $\ldots$ & $\ldots$ & $\ldots$ & $\ldots$ & $\ldots$ & $\ldots$ & $\ldots$ & 82 & $72-95$ & 6.7 & 3.11 & -1.73 & 1.30 & $\ldots$ \\
\hline 3:05 & 189 & u60 & $167-205$ & 5.2 & 2.16 & -0.27 & 2.30 & I & $\ldots$ & $\ldots$ & $\ldots$ & $\ldots$ & $\ldots$ & $\ldots$ & $\ldots$ & $\ldots$ & 116 & $97-129$ & 4.8 & 2.20 & 1.15 & -0.97 & $\ldots$ \\
\hline 4:06 & 127 & n570 & $113-158$ & 6.6 & 2.73 & 1.66 & -2.33 & I & $\ldots$ & $\ldots$ & $\ldots$ & $\ldots$ & $\ldots$ & $\ldots$ & $\ldots$ & $\ldots$ & $\ldots$ & $\ldots$ & $\ldots$ & $\ldots$ & $\ldots$ & $\ldots$ & $\ldots$ \\
\hline 6:05 & $\ldots$ & $\ldots$ & $\ldots$ & $\ldots$ & $\ldots$ & $\ldots$ & $\ldots$ & $\ldots$ & 141 & u113b & $126-171$ & 7.8 & 2.84 & -2.10 & 1.03 & W & 127 & $126-186$ & 4.6 & 2.08 & -1.85 & -1.80 & $\ldots$ \\
\hline 7:04 & 89 & $\mathrm{n} 235 \mathrm{~b}$ & $78-93$ & 7.9 & 3.27 & 2.17 & 0.95 & I & $\ldots$ & $\ldots$ & $\ldots$ & $\ldots$ & $\ldots$ & $\ldots$ & $\ldots$ & $\ldots$ & 78 & 70-79 & 5.2 & 2.34 & 1.67 & -0.26 & 11 \\
\hline 7:05 & $\ldots$ & $\ldots$ & $\ldots$ & $\ldots$ & $\ldots$ & $\ldots$ & $\ldots$ & $\ldots$ & 120 & $\mathrm{n} 235 \mathrm{~b}$ & $102-143$ & 19.5 & 7.6 & 4.18 & 1.8 & I & 132 & $111-143$ & 10.6 & 4.9 & 2.42 & 0.94 & $\ldots$ \\
\hline 8:06 & $\ldots$ & $\ldots$ & $\ldots$ & $\ldots$ & $\ldots$ & $\ldots$ & $\ldots$ & $\ldots$ & 86 & n268 & $72-103$ & 12.0 & 3.74 & -1.41 & 4.01 & $\mathrm{~W}$ & $\ldots$ & $\ldots$ & $\ldots$ & $\ldots$ & $\ldots$ & $\ldots$ & $\ldots$ \\
\hline 9:01 & $\ldots$ & $\ldots$ & $\ldots$ & $\ldots$ & $\ldots$ & $\ldots$ & $\ldots$ & $\ldots$ & 37 & sh1 & $24-49$ & 5.5 & 2.01 & -3.15 & 2.11 & W & $\ldots$ & $\ldots$ & $\ldots$ & $\ldots$ & $\ldots$ & $\ldots$ & $\ldots$ \\
\hline 9:05 & 87 & u114 & 69-103 & 8.2 & 3.45 & 2.39 & 2.16 & I & 88 & u114 & $75-98$ & 15.2 & 5.80 & 3.24 & 2.40 & I & 83 & $62-95$ & 10.7 & 5.03 & 2.87 & 0.31 & $\ldots$ \\
\hline
\end{tabular}

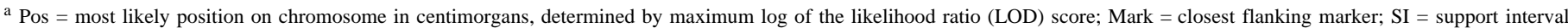
indicates a 1 LOD score drop off from maximum score; $R^{2}=$ percent phenotypic variance explained by $\mathrm{QTL} ; \mathrm{LOD}=$ maximum LOD score; Add = additivity, $1 / 2(\mathrm{QQ}-\mathrm{qq})$; Dom = dominance gene action, 1/2 [(2Qq) - QQ - qq]; and PS = parental source of allele (I = IL731a; W = W6786).

b Chromosomal locations dissected into bins by marker location according to Maize Genetics Newsletter.

${ }^{\mathrm{c}}$ Relevant citations of previously identified QTL in same bin.

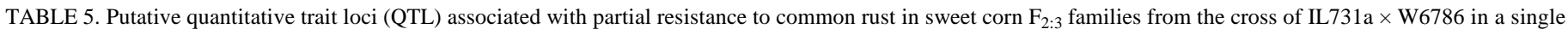
environment over 2 years

\begin{tabular}{|c|c|c|c|c|c|c|c|c|c|c|c|c|c|c|c|c|c|c|c|c|c|c|c|}
\hline \multirow[b]{2}{*}{$\operatorname{Bin}^{a}$} & \multicolumn{8}{|c|}{$1994^{b}$} & \multicolumn{8}{|c|}{1996} & \multicolumn{7}{|c|}{ Combined } \\
\hline & Pos & Mark & SI & $R^{2}$ & LOD & Add & Dom & PS & Pos & Mark & SI & $R^{2}$ & LOD & Add & Dom & PS & Pos & SI & $R^{2}$ & LOD & Add & Dom & $\operatorname{Ref}^{c}$ \\
\hline $1: 03$ & 89 & n286 & 76-109 & 7.7 & 3.21 & 1.40 & -1.20 & I & $\ldots$ & $\ldots$ & $\ldots$ & $\ldots$ & $\ldots$ & $\ldots$ & $\ldots$ & $\ldots$ & 86 & $72-98$ & 7.3 & 3.35 & 0.32 & -0.09 & 34 \\
\hline 2:04 & 56 & u139 & $48-65$ & 7.1 & 2.90 & -1.04 & -1.45 & $\mathrm{~W}$ & 62 & u131 & $40-72$ & 8.6 & 2.93 & -0.55 & 0.04 & W & 57 & $46-68$ & 9.9 & 4.37 & -0.31 & -0.15 & $\ldots$ \\
\hline $2: 05$ & 82 & u131 & $75-94$ & 16.1 & 7.06 & -1.79 & -1.23 & $\mathrm{~W}$ & $\ldots$ & $\ldots$ & $\ldots$ & $\ldots$ & $\ldots$ & $\ldots$ & $\ldots$ & $\ldots$ & $\ldots$ & $\ldots$ & $\ldots$ & $\ldots$ & $\ldots$ & $\ldots$ & $\ldots$ \\
\hline $2: 10$ & 162 & $\mathrm{u} 49$ & $147-163$ & 5.7 & 2.36 & -0.52 & -2.65 & $\mathrm{~W}$ & $\ldots$ & $\ldots$ & $\ldots$ & $\ldots$ & $\ldots$ & $\ldots$ & $\ldots$ & $\ldots$ & 176 & $162-184$ & 6.2 & 2.79 & 0.27 & -0.84 & $\ldots$ \\
\hline $3: 04$ & 96 & u50 & 87-104 & 17.6 & 7.76 & 2.56 & -2.12 & I & 97 & u50 & $66-114$ & 7.3 & 2.52 & 0.54 & -0.41 & I & 96 & 88-104 & 20.0 & 9.86 & 0.54 & -0.31 & 34 \\
\hline 3:06 & $\ldots$ & $\ldots$ & $\ldots$ & $\ldots$ & $\ldots$ & $\ldots$ & $\ldots$ & $\ldots$ & 127 & b15.20 & $116-150$ & 7.4 & 2.55 & 0.49 & -0.34 & I & $\ldots$ & $\ldots$ & $\ldots$ & $\ldots$ & $\ldots$ & $\ldots$ & $\ldots$ \\
\hline $4: 03$ & $\ldots$ & $\ldots$ & $\ldots$ & $\ldots$ & $\ldots$ & $\ldots$ & $\ldots$ & $\ldots$ & $\ldots$ & $\ldots$ & $\ldots$ & $\ldots$ & $\ldots$ & $\ldots$ & $\ldots$ & $\ldots$ & 31 & $10-42$ & 9.6 & 3.98 & -0.33 & -0.24 & 34 \\
\hline $4: 05$ & 136 & n570 & $117-149$ & 5.1 & 2.08 & 0.99 & -0.74 & I & $\ldots$ & $\ldots$ & $\ldots$ & $\ldots$ & $\ldots$ & $\ldots$ & $\ldots$ & $\ldots$ & 187 & $186-192$ & 5.6 & 2.54 & 0.254 & 0.01 & $\ldots$ \\
\hline $5: 02$ & 67 & $a 2$ & $55-77$ & 10.3 & 4.34 & 2.15 & -0.84 & I & $\ldots$ & $\ldots$ & $\ldots$ & $\ldots$ & $\ldots$ & $\ldots$ & $\ldots$ & $\ldots$ & 67 & $54-81$ & 4.9 & 2.24 & 0.22 & 0.08 & $\ldots$ \\
\hline 8:01 & $\ldots$ & $\ldots$ & $\ldots$ & $\ldots$ & $\ldots$ & $\ldots$ & $\ldots$ & $\ldots$ & 6 & n585 & $0-24$ & 12.4 & 2.02 & 0.31 & -0.55 & I & $\ldots$ & $\ldots$ & $\ldots$ & $\ldots$ & $\ldots$ & $\ldots$ & $\ldots$ \\
\hline 8:06 & $\ldots$ & $\ldots$ & $\ldots$ & $\ldots$ & $\ldots$ & $\ldots$ & $\ldots$ & $\ldots$ & $\ldots$ & $\ldots$ & $\ldots$ & $\ldots$ & $\ldots$ & $\ldots$ & $\ldots$ & $\ldots$ & 86 & $72-104$ & 8.3 & 3.18 & -0.31 & 0.01 & $\ldots$ \\
\hline
\end{tabular}

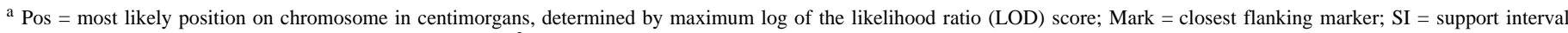
indicates a $1 \mathrm{LOD}$ score drop off from maximum score; $R^{2}=$ percent phenotypic variance explained by $\mathrm{QTL} ; \mathrm{LOD}=$ maximum LOD score; Add = additivity, $1 / 2$ (QQ - qq); Dom = dominance gene action, 1/2 [(2Qq)-QQ - qq]; and PS = parental source of allele (I = IL731a; W = W6786).

${ }^{\mathrm{b}}$ Chromosomal locations dissected into bins by marker location according to Maize Genetics Newsletter.

${ }^{c}$ Relevant citations of previously identified QTL in same bin.

sets, this QTL was also determined to have the largest effect on rust resistance (data not shown).

The major QTL on chromosome 5:03 that is associated with anthocyanin pigmentation maps to the $a 2$ locus. This QTL also maps to within $10 \mathrm{~cm}$ of a QTL identified in this study as associated with partial resistance to Stewart's wilt. Anthocyanin induction has been observed in maize lines resistant to anthracnose (1) and it has been postulated that this may be the result of the induction of phenolics that contribute to both plant defense and anthocyanin accumulation (20). These two QTL may either represent a common step in the phenolic biosynthetic pathway or they may be closely linked genes located in a phenolic/flavanoid gene cluster.

Partial resistance to one or more of these diseases has been noted in maize inbreds whose pedigrees are unrelated to IL677a and which may constitute different sources and, perhaps, different mechanisms of partial resistance. Gingera et al. (15) identified rust-resistant lines with different latent periods characterized by a delayed appearance of the first pustule. The partial resistance to common rust in our study was associated with reduced disease severity and does not necessarily involve latent period. With exception of the QTL on linkage group 7, none of the QTL described by Freymark $(12,13)$ as conferring partial resistance to NCLB were consistent in our study. Ming et al. (38) identified a QTL conferring partial resistance to Stewart's wilt in bin 9:04 that was not significant in our study. It is probable that some of these QTL may be present but not segregating in the current mapping populations. Others may reflect unique genetic factors involved in partial resistance not present in either of our parents. As molecular mapping techniques improve, there is a greater opportunity to identify complimentary sources of partial resistance and consolidate these QTL in populations either through marker-assisted population improvement strategies or through traditional techniques of breeding plants for disease resistance.

Many identified sources of partial resistance to Stewart's wilt, NCLB, and common rust are from field corn inbreds. Their incorporation into sweet corn germ plasm may be impractical due to potential loss of important quality characteristics through linkage drag. Lines related to IL731a, an sul/sel inbred, have been used in the development of a number of commercial hybrids (e.g., Merlin, Miracle, Seneca Sentry, Sugar Buns, Tuxedo, and others). Partial resistance from this source may be of more immediate use in sweet corn. Our results suggest that the QTL for the three diseases are unlinked. Breeding strategies required to transfer these resistances will be more complicated then if they were linked. Few families expressed high levels of resistance to more than one disease, and no single family expressed levels of resistance to all three diseases that were comparable to IL731a. 
TABLE 6. Putative quantitative trait loci (QTL) associated with stalk anthocynin content in $\mathrm{F}_{2: 3}$ families from the cross of IL731a $\times$ W6786 in $1996^{\mathrm{a}}$

\begin{tabular}{llllllll}
\hline Bin $^{\mathrm{b}}$ & Pos & Mark & SI & $R^{2}$ & LOD & Add & Dom \\
\hline $5: 03$ & 90 & a 2 & $85-94$ & 18.1 & 9.6 & 0.50 & 0.30 \\
$10: 06$ & 96 & u44 & $86-104$ & 7.1 & 3.4 & -0.28 & Source \\
\hline
\end{tabular}

${ }^{a}$ Pos $=$ most likely position on chromosome in centimorgans, determined by maximum log of the likelihood ratio (LOD) score; Mark = closest flanking marker; $\mathrm{SI}=$ support interval indicates a $1 \mathrm{LOD}$ score drop off from maximum score; $R^{2}=$ percent phenotypic variance explained by QTL; LOD $=$ maximum LOD score; Add = additivity, 1/2 (QQ - qq); Dom = dominance gene action, 1/2 [(2Qq) $-\mathrm{QQ}-\mathrm{qq}]$; and PS = parental source of allele $(\mathrm{I}=\mathrm{IL731a}$; W = W6786).

${ }^{\mathrm{b}}$ Chromosomal locations dissected into bins by marker location according to Maize Genetics Newsletter.

${ }^{c}$ Parental source of allele (I = IL731a; W = W6786).

TABLE 7. Comparison of quantitative trait loci (QTL) position of statistically significant QTL associated with partial resistance in the population of sweet corn to Stewart's wilt, northern corn leaf blight (NCLB), and common rust in two environments as determined by composite interval mapping using the complete data set and by the frequency distribution of significant QTL position by 100 partial data sets ${ }^{\mathrm{a}}$

\begin{tabular}{|c|c|c|c|c|c|c|}
\hline \multirow[b]{3}{*}{ Disease } & \multicolumn{4}{|c|}{ QTL position } & & \\
\hline & \multicolumn{2}{|c|}{ Complete $^{\mathrm{b}}$} & \multicolumn{2}{|c|}{ Frequency sets ${ }^{\mathrm{c}}$} & \multicolumn{2}{|c|}{ Partial data $(\%)^{\mathrm{d}}$} \\
\hline & Year 1 & Year 2 & Year 1 & Year 2 & Year 1 & Year 2 \\
\hline Stewart's wilt & $5: 86$ & $5: 93$ & $5: 86$ & $5: 92$ & 81 & 54 \\
\hline Stewart's wilt & $6: 90$ & $6: 86$ & $6: 86$ & $6: 86$ & 80 & 53 \\
\hline NCLB & $9: 87$ & $9: 88$ & $9: 74$ & $9: 86$ & 62 & 67 \\
\hline Common rust & $2: 56$ & $2: 62$ & $2: 56$ & $2: 56$ & 79 & 46 \\
\hline
\end{tabular}

a Year $1=1994$ for all diseases, Year $2=1995$ for Stewart's wilt and 1996 for NCLB and common rust.

${ }^{b}$ QTL position as determined by maximum log of the likelihood ratio (LOD) score with composite interval mapping generated from the original data set (linkage group and position from distal end of linkage group).

${ }^{c}$ QTL position as determined by the peak of the frequency distribution of maximum LOD scores generated from 100 partial data sets .

${ }^{\mathrm{d}}$ Percentage of 100 cross validation estimation sets that identified a significant QTL with an LOD score of at least 2.00 within the original data sets confidence interval.

\section{LITERATURE CITED}

1. Bergstrom, G. C., and Nicholson, R. L. 1999. The biology of corn anthracnose. Plant Dis. 83:596-608.

2. Blanco, M. H., Johnson, M. G., Colbert, T. R., and Zuber, M. S. 1977. An inoculation technique for Stewart's wilt disease of corn. Plant Dis. Rep. 61:413-416.

3. Braun, E. J. 1982. Ultrastructural investigations of resistant and susceptible maize inbreds infected with Erwina stewartii. Phytopathology 72:159-166.

4. Brewster, V. A., Carson, M. L., and Wicks, Z. W. 1992. Mapping components of partial resistance to northern leaf blight of maize using reciprocal translocations. Phytopathology 82:225-229.

5. Carson, M. L. 1995. Inheritance of latent period length in maize infected with Exserohilum turcicum. Plant Dis. 79:581-585.

6. Chang, C. M., Hooker, A. L., and Lim, S. M. 1977. An inoculation technique for determining Stewart's bacterial leaf blight reaction in corn. Plant Dis. Rep. 61:1077-1079.

7. Coe, E. H. 1995. Gene list and working maps. Maize Genet. Coop. Newsl. 69:133-168.

8. Davis, D. W., Randle, W. M., and Groth, J. V. 1988. Some sources of partial resistance to common leaf rust (Puccinia sorghi) in maize and strategy for screening. Maydica 33:1-13.

9. Dingerdissen, A. L., Geiger, H. H., Lee, M., Schechert, A., and Welz, H. G. 1996. Interval mapping of genes for quantitative resistance to Setospheria turcica, cause of northern leaf blight, in a tropical environment. Mol. Breed. 2:143-156.

10. Elliot, C., and Jenkins, M. T. 1946. Helminthosporium turcicum leaf blight of corn. Phytopathology 36:660-666.

11. Ferguson, J. E., Rhodes, A. M., and Dickenson, D. B. 1979. Analysis of endosperm sugars in a sweet corn inbred (Il677a) which contains the sugary enhancer gene (se) and comparisons of se with other corn genotypes. Plant Physiol. 63:416-420.

12. Freymark, P. J., Lee, M., Martinson, C. A., and Woodman, W. L. 1994. Molecular-marker-facilitated investigation of host-plant response to $E x$ serohilum turcicum in maize (Zea Mays L.): Components of resistance. Theor. Appl. Genet. 88:305-313.

13. Freymark, P. J., Lee, M., Woodman, W. L., and Martinson, C. A. 1993. Quantitative and qualitative trait loci affecting host-plant response to Exserohilum turcicum in maize (Zea mays L.). Theor. Appl. Genet. 87:537-544.

14. Geivers, H. O. 1975. A new major gene for resistance to Helminthosporium turcicum leaf blight of maize. Plant Dis. Rep. 59:296-299.

15. Gingera, G. R., Davis, D. W., and Groth, J. V. 1995. Identification and inheritance of delayed first pustule appearance to common leaf rust in sweet corn. J. Am. Soc. Hortic. Sci. 120:667-672.

16. Groth, J. V., Davis, D. W., Zeyen, R. J., and Morgann, B. D. 1983. Ranking of partial resistance to common rust (Puccinia sorghi Schew.) in 30 sweet corn (Zea mays) hybrids. Crop Prot. 2:105-111.

17. Groth, J. V., Pataky, J. K., and Gingera, G. R. 1992. Virulence in eastern North American populations of Puccinia sorghi to $R p$ resistance genes in corn. Plant Dis. 76:1140-1144.

18. Haley, C. S., and Knott, S. A. 1992. A simple regression method for mapping quantitative trait loci in line crosses using flanking markers. Heredity 69:315-324.

19. Hallauer, A. R., and Miranda, J. B. 1988. Quantitative Genetics in Maize Breeding. 2nd ed. Iowa State University Press, Ames.

20. Hammerschmidt, R., and Nicholson, R. L. 1977. Resistance of maize to anthracnose: Changes in host phenols and pigments. Phytopathology 67:251-258.

21. Hooker, A. L. 1961. A new type of resistance in corn to Helminthosporium turcicum. Plant Dis. Rep. 57:780-781.

22. Hooker, A. L. 1963. Monogenic resistance in Zea mays L. to Helminthosporium turcicum. Crop Sci. 3:381-383.

23. Hooker, A. L. 1977. A second major locus in corn for chlorotic-lesion resistance to Helminthosporium turcicum. Crop Sci. 17:132-135.

24. Hooker, A. L. 1978. Additional sources of monogenic resistance in corn to Helminthosporium turcicum. Crop Sci. 18:787-788.

25. Hooker, A L. 1985. Corn and sorghum rusts. Pages 207-236 in: The Cereal Rusts. A. P. Roelfs and W. R. Bushnell, eds. Academic Press, New York.

26. Hooker, A. L., and Kim, S. K. 1973. Monogenic and multigenic resistance to Helminthosporum turcicum in corn. Plant Dis. Rep. 61: 586-589.

27. Jansen, R. C. 1993. Maximum likelihood in a generalized linear finite mixture model by using the EM algorithm. Biometrics 49:227-231.

28. Jenkins, M. T., Robert, A. L., and Findley, W. R. 1957. Genetic studies of resistance to Helminthosporium turcicum in maize by means of chromosomal translocations. Agron. J. 49:197-201.

29. Juvik, J. A., Rouf Mian, M. A., and Faber, A. J. 1994. Sugary1 and sugary enhancerl sweet corn inbreds with resistance to northern corn leaf blight. Hortscience 29:1369-1370.

30. Kerns, M. R., Dudley, J. W., and Rufener, G. K. 1999. QTL for resistance to common rust and smut in maize. Maydica 44:37-45.

31. Kim, S. K., and Brewbaker, J. L. 1987. Inheritance of resistance of sweet corn inbred Il677a to Puccinia sorghi. Hortscience 22:1319-1320.

32. Knapp, S. J., Stroup, W. W., and Ross, W. M. 1985. Exact confidence intervals for heritability on a progeny mean basis. Crop Sci. 25:192-194.

33. Lander, E. S., Green, P., Abrahamson, J., Barlow, A., Daly, M. J., Lincoln, S. E., and Newburg, L. 1987. Mapmaker: An interactive com- 
puter package for constructing primary linkage maps of experimental and natural populations. Genomics 1:174-181.

34. Leonards-Schippers, C., Gieffers, W., Schafer-Pregl, R., Ritter, E., Knapp, S. J., Salamini, F., and Gebhardt, C. 1994. Quantitative resistance to Phytophthora infestans in potato: A case study for QTL mapping in an allogamous plant species. Genetics 137:67-77.

35. Lubberstedt, T., Klein, D., and Melchinger, A. E. 1998. Comparative quantitative trait loci mapping of partial rust resistance to Puccinia sorghi across four populations of European flint maize. Phytopathology 88:1324-1329.

36. McMullen, M. D., and Simcox, K. D. 1995. Genomic organization of disease and insect resistance genes in maize. Mol. Plant-Microbe Interact. 8:811-815.

37. Meyer, A. C., Pataky, J. K., and Juvik, J. A. 1991. Partial resistance to northern corn leaf blight and Stewart's wilt in sweet corn germ plasm. Plant Dis. 75:1094-1097.

38. Ming, R., Brewbaker, J. L., Moon, H. G., Musket, T. A., Holley, R., Pataky, J. K., and McMullen, M. D. 1999. Identification of RFLP markers linked to a major gene, $s w 1$, conferring resistance to Stewart's wilt in maize. Maydica 44:319-323.

39. Nass, H. A., Pederson, W. L., Mackenzie, D. R., and Nelson, R. R. 1981. The residual effects of some defeated powdery mildew resistance genes in isolines of winter wheat. Phytopathology 71:315-318.

40. Nelson, R. R. 1978. Genetics of horizontal resistance to plant diseases. Annu. Rev. Phytopathol. 16:359-378.

41. Pataky, J. K. 1986. Partial rust resistance in sweet corn hybrid seedlings. Phytopathology 76:702-707.

42. Pataky, J. K., and Eastburn, D. M. 1993. Using hybrid disease nurseries and yield loss studies to evaluate levels of resistance in sweet corn. Plant Dis. 77:760-765.

43. Pataky, J. K., Headrick, J. M., and Suparyono. 1988. Classification of sweet corn hybrid reaction to common rust, northern corn leaf blight, Stewart's wilt, and Gross' wilt and associated yield reduction. Phytopathology 78:172-178.

44. Pataky, J. K., and Mosely, P. R. 1995. Successful use of resistance to control diseases of sweet corn. Plant Dis. 79:1256-1258.

45. Pataky, J. K., and Tracy, W. F. 1999. Widespread occurrence of common rust, caused by Puccinia sorghi, on Rp-resistant sweet corn in the Midwestern United States. Plant Dis. 83:1177.
46. Peterson, R. F., Cambell, A. B., and Hannah, A. E. 1948. A diagrammatic scale for estimating rust intensity on leaves and stems of cereals. Can. J. Res. Sect. C 26:496-500.

47. Rhodes, A. M., Carey, E. E., and Dickenson, B. D. 1982. Illinois sweet corn inbreds with the su se genotype. Hortscience 17:411-412.

48. Robbins, W. A., and Warren, H. L. 1993. Inheritance of resistance to Exserohilum turcicum in PI 209135 'Mayorbella' variety of maize. Maydica 38:209-213.

49. Sanz-Alferez, S., Richter, T. E., and Hulbert, S. H. 1995. The Rp3 disease resistance gene of maize: Mapping and characterization of introgressed alleles. Theor. Appl. Genet. 91:25-32.

50. Stuber, C. W., Edwards, M. D., and Wendel, J. F. 1987. Molecular marker-facilitated investigations of quantitative trait loci in maize. II. Factors influencing yield and its component traits. Crop Sci. 27:639-648.

51. Suparyono, and Pataky, J. K. 1989. Influence of host resistance and growth stage at the time of inoculation on Stewart's wilt and Goss's wilt development and sweet corn hybrid yield. Plant Dis. 73:339-345.

52. Tadmor, Y., Azanza, F., Han T., Rocheford, T. R., and Juvik, J. A. 1995. RFLP mapping of the sugary enhancerl gene in maize. Theor. Appl. Genet. 91:489-494.

53. Utz, H. P., and Melchinger, A. E. 1995. PLABQTL. A computer program to map QTL. J. Quant. Trait Loci. vol. 2, paper 1. Sponsored by the Crop Science Society of America.

54. Utz, H. P., Melchinger, A. E., and Schon, C. S. 2000. Bias and sampling error of the estimated proportion of genotypic variance explained by quantitative trait loci determined from experimental data in maize using cross validation and validation with independent samples. Genetics 154:1839-1849.

55. Vanderplank, J. E. 1968. Disease Resistance in Plants. Academic Press, New York.

56. Wang, G.-L., Mackill, D. J., Bonman, J. M., McCouch, S. R., Champoux, M. C., and Nelson, R. J. 1994. RFLP mapping of genes conferring complete and partial resistance to blast in a durably resistant rice cultivar. Genetics 136:1421-1434.

57. Young, N. D. 1996. QTL mapping and quantitative disease resistance in plants. Annu. Rev. Phytopathol. 34:479-501.

58. Young, N. D., Zamir, D., Ganal, M. W., and Tanksley, S. D. 1986. Use of isogenic lines and simultaneous probing to identify DNA markers tightly linked to the Tm-2 gene in Tomato. Genetics 120:579-585. 